\title{
MOCVD Growth and Fabrication of High Power MUTC Photodiodes Using InGaAs-InP System
}

\author{
Nandan Singh, Charles Kin Fai Ho, Guo Xin Tina, Manoj Kumar Chandra Mohan, \\ Kenneth Eng Kian Lee, Hong Wang, and Huy Quoc Lam
}

\author{
Temasek Laboratories, Nanyang Technological University (TL@NTU), 50 Nanyang Drive, Singapore 637553 \\ Correspondence should be addressed to Nandan Singh; nandan@ntu.edu.sg
}

Received 13 August 2015; Revised 30 October 2015; Accepted 1 November 2015

Academic Editor: Meiyong Liao

Copyright (c) 2015 Nandan Singh et al. This is an open access article distributed under the Creative Commons Attribution License, which permits unrestricted use, distribution, and reproduction in any medium, provided the original work is properly cited.

\begin{abstract}
We report charge-compensated modified uni-traveling-carrier photodiodes (MUTC-PDs) with high photocurrent and fast response, grown using liquid group-V precursor, in an AIXTRON MOCVD system. The liquid group-V precursors involve less toxicity with better decomposition characteristics. Device fabrication is completed with standard processing techniques with $\mathrm{BCB}$ passivation. DC and RF measurements are carried out using a single mode fiber at $1.55 \mu \mathrm{m}$. For a $24-\mu \mathrm{m}$-diameter device (with diode ideality factor of 1.34), the dark current is $32.5 \mathrm{nA}$ and the $3-\mathrm{dB}$ bandwidth is $\gg 20 \mathrm{GHz}$ at a reverse bias of $5 \mathrm{~V}$, which are comparable to the theoretical values. High photocurrent of over $150.0 \mathrm{~mA}$ from larger diameter $(>60 \mu \mathrm{m})$ devices is obtained. The maximum DC responsivity at $1.55 \mu \mathrm{m}$ wavelength is $0.51 \mathrm{~A} / \mathrm{W}$, without antireflection coating. These photodiodes play a key role in the progress of the future $\mathrm{THz}$ communication systems.
\end{abstract}

\section{Introduction}

High performance photodiode is a key enabler for highspeed RF-over-optical carrier communications $[1,2]$. In addition to high bandwidth and high responsivity, these photodiodes should be able to handle large optical power. Therefore, these photodiodes should be able to provide very high photocurrent level and, thus, high RF output power in these optical links. One of the primary factors that limit the saturation power of a photodiode is the carrier screening of the internal electric field, which is frequently referred to as the space-charge effect. Several photodiode structures have been designed to reduce the space-charge effect and hence achieve high-speed with better responsivity, for example, the PINphotodiode [3], the uni-traveling-carrier photodiode (UTCPD) [4], the partially depleted-absorber photodiode [5], and the dual-depletion region photodiode [6]. In PIN-type photodetectors, the drift time of holes has to be minimized since the low mobility of holes is a factor limiting the speed of the photodetectors [7]. On the other hand, the electron diffusion time through the p-type photoabsorption layer should be minimized for UTC-PDs. Since the diffusion-limited transit time is proportional to the square of the thickness of the p-type photoabsorption layer, the thickness is typically limited to less than $0.2 \mu \mathrm{m}$ for UTC-PDs having bandwidths greater than $100 \mathrm{GHz}$ [8]. The UTC structure utilizes an undepleted p-layer to absorb light and inject electrons into a nonabsorbing drift region. Having only electrons in the depletion region greatly suppresses the space-charge effect. Because only electrons are the active carriers in the UTC-PD, the slow hole transport is eliminated and the bandwidth and saturation-current performance is improved. In this work the UTC device structure from Campbell group [9] was adopted and was modified for the absorption and collection layers thickness to achieve simultaneous high power and fast response. Such high power and large bandwidth devices play a key role in the future $\mathrm{THz}$ technology, especially material systems which operate at long optical wavelengths $(1.3-1.55 \mu \mathrm{m})[10-12]$.

To achieve high performance in a photodiode, growth of high quality epitaxial layers with low defects is essential. Metalorganic chemical vapor deposition (MOCVD) technique has been widely used for the realization of high quality III$\mathrm{V}$ based photonic and optoelectronic epitaxial structures. In 
general MOCVD process uses the toxic hydrides $\mathrm{PH}_{3}$ and $\mathrm{AsH}_{3}$ as group-V precursors. The liquid group-V precursors tertiarybutylarsine (TBAs) and tertiarybutylphosphine (TBP), with reduced toxicity and improved decomposition characteristics, have been used as substitute for the highly toxic hydrides $[13,14]$. Better decomposition characteristics allow a reduction in growth temperature and V/III ratio, leading to a more efficient deposition process and a significant reduction in the arsenic waste material. Devices made from structures grown with TBAs and TBP exhibit state of the art performance [14]. The compositional uniformity of quaternary (InGaAsP) material is significantly enhanced using TBAs and TBP [13]. In this work, we investigate MUTC-PD structure to achieve both high power and high speed. These photodetectors can achieve simultaneously a high responsivity of $0.51 \mathrm{~A} / \mathrm{W}$ (without $\mathrm{ARC}$ ) with a high photocurrent of over $150 \mathrm{~mA}$ with $-3 \mathrm{~dB}$ bandwidth of $\sim 3 \mathrm{GHz}$. The smaller diameter devices can achieve high band width with large photocurrent.

\section{MUTC Design and Fabrication}

The InP-InGaAs epitaxial device structures used in this work were grown in AIXTRON 200 horizontal MOCVD reactor on semi-insulating (100) InP substrates at 100 mbar chamber pressure and $630^{\circ} \mathrm{C}$ substrate temperature under nitrogen ambient. In this epitaxial growth, the precursors used were tertiarybutylarsine (TBAs), tertiarybutylphosphine (TBP), trimethylindium (TMIn), and trimethylgallium (TMGa). Dimethylzinc $(\mathrm{DMZn})$ and Silane $\left(\mathrm{SiH}_{4}\right)$ were used for $\mathrm{p}$ - and n-type doping, respectively. The use of the liquid group-V precursors TBAs and TBP instead of $\mathrm{AsH}_{3}$ and $\mathrm{PH}_{3}$ significantly increases the $\mathrm{SiH}_{4}$ doping efficiency [15]. Better crystalline quality and composition controllability can be achieved even at relatively lower V/III using TBAs and TBP [16]. The growth rate, compositions, and doping concentration of the individual layers were determined by characterizing the 350-400 nm thick single InP, InGaAs, and InGaAsP layers.

A schematic cross-section of the device structure is shown in Table 1, with the band diagram is shown in Figure 1. The two 15-nm undoped quaternary InGaAsP $1.1 \mu \mathrm{m}$ (Q1.1) \& InGaAsP $1.4 \mu \mathrm{m}$ (Q1.4) layers were used to smoothen the abrupt conduction band barrier at the InGaAs-InP heterojunction interface. To help carrier transport in the doped absorbing layer, the doping of the InGaAs absorbing region was graded in four steps to create a quasi-electric field. The 350-nm-thick p-InP layer was used to block electron diffusion toward the top surface. In the depletion region, the 200-nm InP layer was n-type-doped to $1 E+16 \mathrm{~cm}^{-3}$, as charge compensation. The depleted InGaAs absorbing layer was also doped to compensate the space charge. The devices were fabricated for front illumination using a mesa isolation process. Ti-Au was used for both $\mathrm{p}$ - and n-type Ohmic contacts. The devices were passivated using BCB. Top-illuminated UTC-PDs with cylindrical MESAs of different diameters were fabricated using standard processing techniques. The mesa formation was based on wet etching processes to minimize the surface damage. The mesa was
TABLE 1

\begin{tabular}{lcc}
\hline Material & Doping & Thickness \\
\hline p-InGaAs & $\mathrm{Zn}, 2 E+19$ & $60 \mathrm{~nm}$ \\
p-InP & $\mathrm{Zn}, 3 E+18$ & $350 \mathrm{~nm}$ \\
p-InGaAs & $\mathrm{Zn}, 2 E+18$ & $75 \mathrm{~nm}$ \\
p-InGaAs & $\mathrm{Zn}, 1 E+18$ & $100 \mathrm{~nm}$ \\
p-InGaAs & $\mathrm{Zn}, 5 E+17$ & $150 \mathrm{~nm}$ \\
p-InGaAs & $\mathrm{Zn}, 2.5 E+17$ & $150 \mathrm{~nm}$ \\
n-InGaAsP & $\mathrm{Si}, 1 E+16$ & $200 \mathrm{~nm}$ \\
n-InGaAs, Q1.4 & - & $15 \mathrm{~nm}$ \\
InGaAsP, Q1.1 & - & $15 \mathrm{~nm}$ \\
n-InP & $\mathrm{Si}, 1 E+16$ & $150 \mathrm{~nm}$ \\
n-InP & $\mathrm{Si}, 1 E+19$ & $200 \mathrm{~nm}$ \\
n-InGaAs & $\mathrm{Si}, 1 E+19$ & $20 \mathrm{~nm}$ \\
n-InP buffer & $\mathrm{Si}, 1 E+19$ & $200 \mathrm{~nm}$ \\
InP substrate & Semi-Insulating & $350 \mu \mathrm{m}$ \\
\hline
\end{tabular}
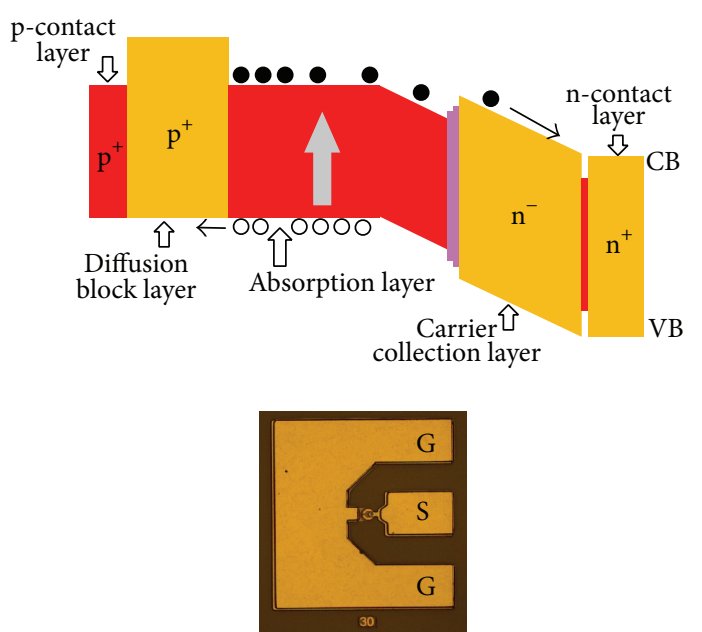

FIGURE 1: Details of the grown MUTC-PD structure parameters (see Table 1) and the figure show the band diagram of the MUTC-PD structure with a top view of the real device with G-S-G (GroundSignal-Ground) electrodes.

connected to the coplanar waveguide for RF probing with BCB planarization. Microwave contact pads and air-bridge connection to the $\mathrm{p}$-InGaAs contact layer were fabricated for high speed measurements. The photoresponsivity and high speed response characteristics of PD devices were tested in an Agilent Lightwave Component Analyzer (LCA) system N4373A, incorporated with a Keopsys high power erbiumdoped optical power amplifier (EDFA).

\section{Results and Discussion}

3.1. Material Growth. Figure 2 shows the microscopic and crystallographic characterizations on as-grown MUTC-PD wafers. Selective InGaAs wet etch over InP (using $\mathrm{H}_{3} \mathrm{PO}_{4}$, $\mathrm{H}_{2} \mathrm{O}_{2}$ and $\mathrm{H}_{2} \mathrm{O}$ ) was performed for 20 seconds to provide the layer contrast to X-SEM images in Figures 2(a) and 2(b). The wafer was grown at $630^{\circ} \mathrm{C}$ (Figure 2(b)), with smooth 


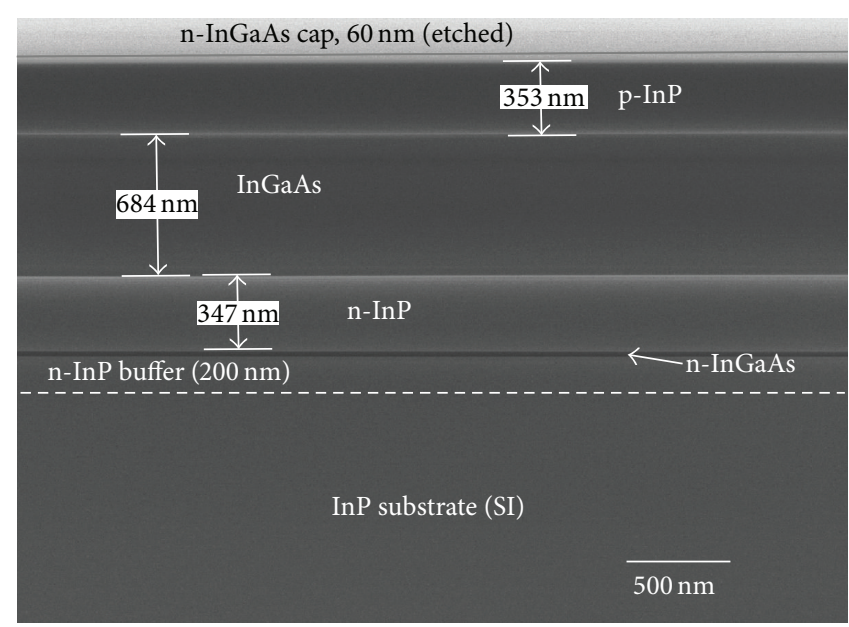

(a)

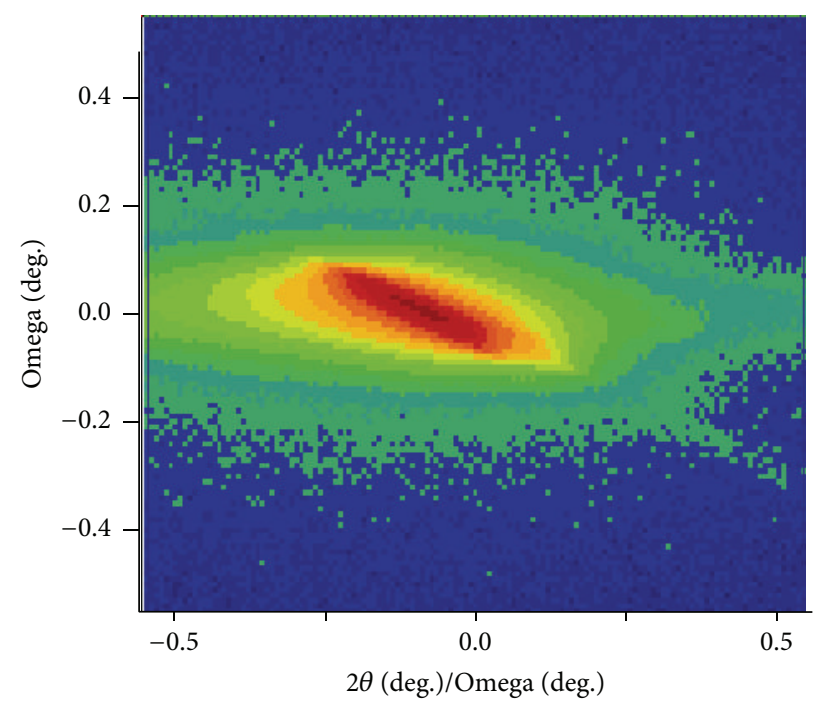

(b)

FIgURE 2: (a) Cross-section SEM image of the InGaAs etched MUTC-PD device structure and (b) shows the high resolution reciprocal space map along $\langle 004\rangle$ of InP system.

and abrupt interfaces and layered top surface which appears shiny to the naked eyes. Figure 2(b) shows the HR-XRD characterization performed on the as-grown MUTC-PD wafers, measured in a Panalytical X'pert Pro diffractometer. Only a single peak was observed in the reciprocal space mapping (RSM) measured along $\langle 004\rangle$ in Figure 2(b), which shows the lattice matched epilayers of InGaAs on InP.

All epilayers have been grown and studied individually (400 nm thick) for composition, band gap, doping, growth rate, and surface roughness, before the final full structure MUTC-PD device structure growth. Highly doped single SiInP $(1 E+19)$ layers were also investigated for the doping concentration and surface roughness. At growth temperature of $630^{\circ} \mathrm{C}$ a smooth and shiny Si-InP $(1 E+19)$ layer was obtained. At lower growth temperatures this highly doped SiInP layer showed some roughness. The dopant incorporation in MOCVD is dominated by chemistry and thermodynamics of the doping and growth process. At low growth temperatures, incorporation of impurity atoms ( $\mathrm{Zn}$ and $\mathrm{Si}$ in this case) would be limited by kinetic barriers that make it difficult for atoms to acquire thermal equilibrium positions which may result in undesired doping profiles. The incorporation of $\mathrm{Zn}$ becomes strongly dependent on growth temperature. Also, $\mathrm{Zn}$ doping is limited by desorption and diffusion of $\mathrm{Zn}$ from the growing crystal surface. At growth temperature of $\sim 630^{\circ} \mathrm{C}$, a low Zn diffusion coefficient of $7 \times 10^{-17} \mathrm{~cm}^{2} / \mathrm{s}$ (at doping concentration of $1 \times 10^{18} \mathrm{~cm}^{-3}$ ) is reported by Enquist et al. [17]. Such low diffusion coefficients make feasible the abrupt $\mathrm{Zn}$ doping profiles which are required in heterostructure devices. Also the coefficient is dependent on the $\mathrm{Zn}$ concentration, which increases with the $\mathrm{Zn}$ concentration.

3.2. DC Measurements. As shown in Figure 3(a), a low dark current of $32.5 \mathrm{nA}$ and $60.2 \mathrm{nA}$ at a reverse bias of $5 \mathrm{~V}$ has been measured from smaller device with diameter $24 \mu \mathrm{m}$ and from large device with diameter of $80 \mu \mathrm{m}$, respectively. In comparison, Campbell group have reported a dark current of $\sim 100 \mathrm{nA}$ at $6 \mathrm{~V}$ for a $20 \mu \mathrm{m}$ device [18], which is comparable to our large $80 \mu \mathrm{m}$ device at $6 \mathrm{~V}$. This low dark current in our devices allows the operations at higher reverse biases which helps to achieve high RF output power [4]. The dark currents in junction photodiodes are relevant to the generation in the space charge region, diffusion from the quasi-neutral regions, and surface leakage. Low surface leakage is most important for the vertical mesa device structure. Thus, a desired etch profile and effective passivation are very important for the UTC-PD to reduce the sidewall leakage current. Room temperature DC characterization reveals a diode ideality factor of 1.34 for $24 \mu \mathrm{m}$ device in the range of 0.1 to $0.45 \mathrm{~V}$. The ideality factor is a figure of merit that describes the recombination behavior of the device. Recombination can occur at interfaces, thus the ideality factor is a manifestation of the density and quality of interfaces. The ideality factor of 1.34 in our device indicates that a large amount of current is due to diffusion and is not dominated by recombination. The dark current was normalized against the area of respective devices to evaluate the material quality (Figure 3(b)). Larger devices show lower normalized dark current, indicating that the dark current is dominated by surface effects. It implies that there is minimal leakage through the bulk of the device, indicating the better material quality of the grown epitaxial layers.

DC measurements were carried out with a monochromatic light source at $1.55 \mu \mathrm{m}$ under different reverse bias voltages. The light was normal incident on the top surface of the device. The performances of different devices under different optical excitation and electrical bias are summarized in Table 2. A maximum photocurrent of $150.5 \mathrm{~mA}$ was obtained at $9 \mathrm{~V}$ from $80 \mu \mathrm{m}$ device, and the device failure occurred at $11 \mathrm{~V}$. In $80 \mu \mathrm{m}$ device, a series resistance of $5.5 \Omega$ 


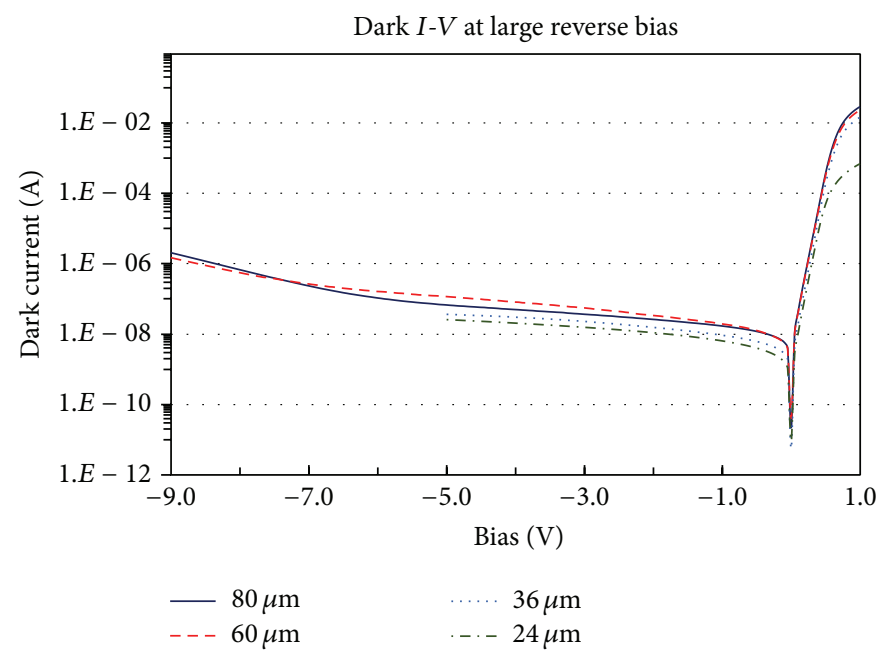

(a)

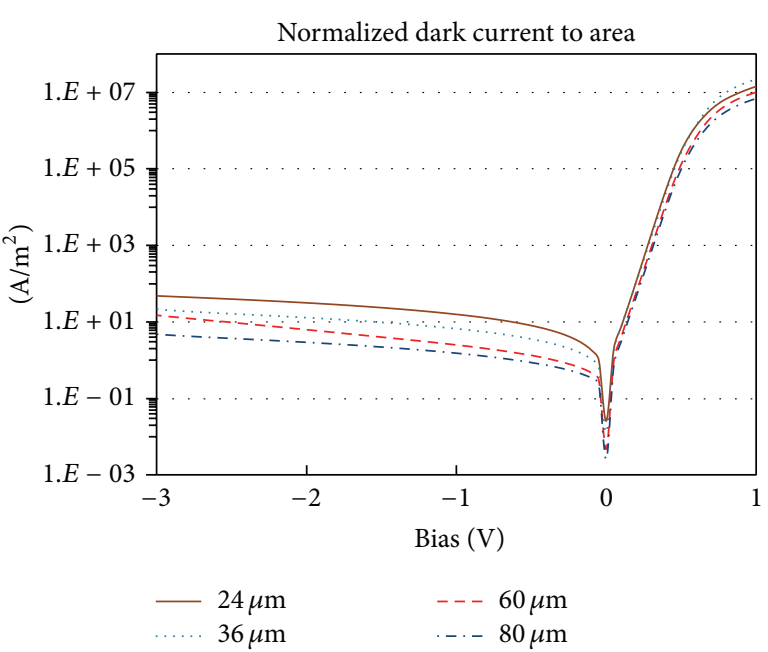

(b)

Figure 3: (a) Dark current measured from different devices under large reverse bias, and (b) shows normalized dark current to area of different devices.

TABle 2: Summary of photocurrent for different devices under different bias and incident optical power.

\begin{tabular}{lccc}
\hline \multirow{2}{*}{ Device diameter/incident power } & \multicolumn{4}{c}{ Photocurrent, mA (no ARC) } \\
& $4 \mathrm{~V}$ & $5 \mathrm{~V}$ & $6 \mathrm{~V}$ \\
\hline $24 \mu \mathrm{m} / 21.7 \mathrm{dBm}$ & 25.1 & 25.8 & 26.2 \\
$30 \mu \mathrm{m} / 23 \mathrm{dBm}$ & 45.2 & 48.5 & 51.0 \\
$44 \mu \mathrm{m} / 23 \mathrm{dBm}$ & 57.5 & 62.3 & 65.1 \\
$50 \mu \mathrm{m} / 26 \mathrm{dBm}$ & 94.5 & 100.3 & 102.8 \\
$80 \mu \mathrm{m} / 28.4 \mathrm{dBm}$ & 125.6 & 136.5 & 144.5 \\
\hline
\end{tabular}

was extracted from the forward bias dark $I-V$ curve [19]. At the applied optical wavelength of $1.55 \mu \mathrm{m}$, DC responsivity of $0.51 \mathrm{~A} / \mathrm{W}$ at $9 \mathrm{~V}$ and $100 \mathrm{~mW}$ incident optical power was measured without antireflection coated (ARC) facets. This responsivity was calculated assuming no optical losses, for example, coupling loss, reflection, and over spilling in smaller devices. In comparison, Chtioui et al. [20] have reported $\sim 0.55 \mathrm{~A} / \mathrm{W}$ at $1.55 \mu \mathrm{m}$ for an absorption layer thickness of $600 \mathrm{~nm}$ and Campbell group [9] have reported a responsivity of $0.75 \mathrm{~A} / \mathrm{W}$, with ARC, for similar MUTC-PD structure with absorption layer of $850 \mathrm{~nm}$.

3.3. $R F$ Measurements. Figure 4(a) shows the normalized $\mathrm{RF}$ response, which is limited by our measurement system at $20 \mathrm{GHz}$. The RF performance of different devices at $5 \mathrm{~V}$ is summarized in Table 3. The 3-dB bandwidth of a $24 \mu \mathrm{m}$ device could not be measured completely due to using $20 \mathrm{GHz}$ network analyzer. The smaller devices with diameter $24 \mu \mathrm{m}$ has shown large $-3 \mathrm{~dB}$ band width of $\gg 20 \mathrm{GHz}$ at $19.5 \mathrm{~mA}$ photocurrent. Larger diameter devices, $80 \mu \mathrm{m}$ diameter device, have shown high photocurrent of $149 \mathrm{~mA}$ with $2.8 \mathrm{GHz}$ at $7 \mathrm{~V}$. Results in Table 3 indicate that bandwidths of larger devices $80 \mu \mathrm{m}, 50 \mu \mathrm{m}$, and $30 \mu \mathrm{m}$ are RC-limited; however for the smaller devices with diameter below $24 \mu \mathrm{m}$, carrier transit time through absorption and collection layer play significant role. Compared to the UTC structures [21], the speed of MUTC structure is higher for similar size mainly because of the thicker depletion region which plays important part in the RC-limited bandwidth. It can be concluded that in our MUTC-PD wafer the band width of the smaller devices are limited by transit time and larger devices are RC-limited. The saturation current-bandwidth products for the respective devices are shown in Table 3 . Our $30 \mu \mathrm{m}$ device shows a saturation current-bandwidth product of $716 \mathrm{~mA} \cdot \mathrm{GHz}$. In comparison, Campbell group [9] have reported a saturation current-bandwidth product of $1560 \mathrm{~mA} \cdot \mathrm{GHz}$ from a $40 \mu \mathrm{m}$ device. Our smaller devices are capable of achieving comparable results after adding ARC on the top layer. The comparison of the performance of the high power MUTC-PD device achieved in this work with various other reports in literature is shown in Figure 4(b). It can be observed that our MUTC-PD device performance is comparable with the other high current devices [5, 9, $20,22]$. The thinner absorption and collection layers used in this work have shown improved bandwidth for smaller diameter devices and larger devices were able to achieve high photocurrent. These high bandwidth devices play a key role in realizing the future $\mathrm{THz}$ communication systems $(30 \mathrm{GHz}-10 \mathrm{THz})$ which can allow transmitting data with a high rate $[10,11]$. Especially for THz-wave applications, UTCPDs have shown promising performance in output power and operation frequency compared with conventional $\mathrm{p}-\mathrm{i}-\mathrm{n}$ type PDs [12].

\section{Conclusion}

In summary, the epilayers grown at intermediate temperature of $630^{\circ} \mathrm{C}$ using liquid group-V precursors TBAs and TBP, with a small ideality factor and low dark current, have shown good material quality with sharp interfaces and shiny 
TABLE 3: Summary of the RF responses of different devices with corresponding photocurrent at 5 V. The calculated RC bandwidth includes the $50 \Omega$ load resistance.

\begin{tabular}{lcccccc}
\hline Diameter $(\mu \mathrm{m})$ & $\begin{array}{c}\text { Photocurrent } \\
(\mathrm{mA}) \text { at } 5 \mathrm{~V}\end{array}$ & $R_{\text {Series }}(\Omega)$ & $C(\mathrm{pF})$ & RC bandwidth $(\mathrm{GHz})$ & 3-dB bandwidth $(\mathrm{GHz})$ & mA.GHz \\
\hline 24 & 19.5 & 24.5 & 0.065 & 32.7 & NA \\
30 & 37.5 & 21.0 & 0.116 & 19.3 & 19.1 & 5.5 \\
50 & 100.5 & 12.0 & 0.448 & 5.76 & 20 & 2.8 \\
80 & 136.5 & 5.5 & 1.020 & 2.82 & 417.2 at 7 V \\
\hline
\end{tabular}

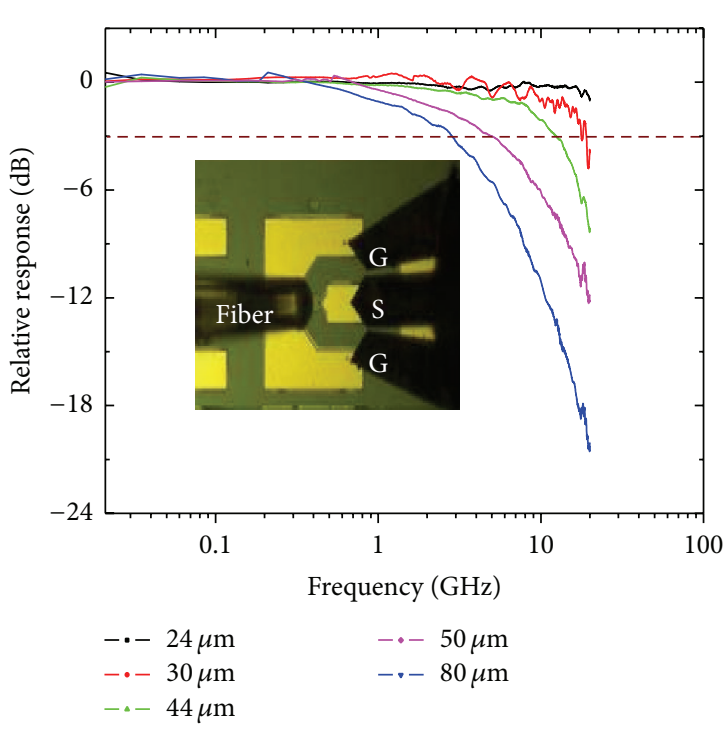

(a)

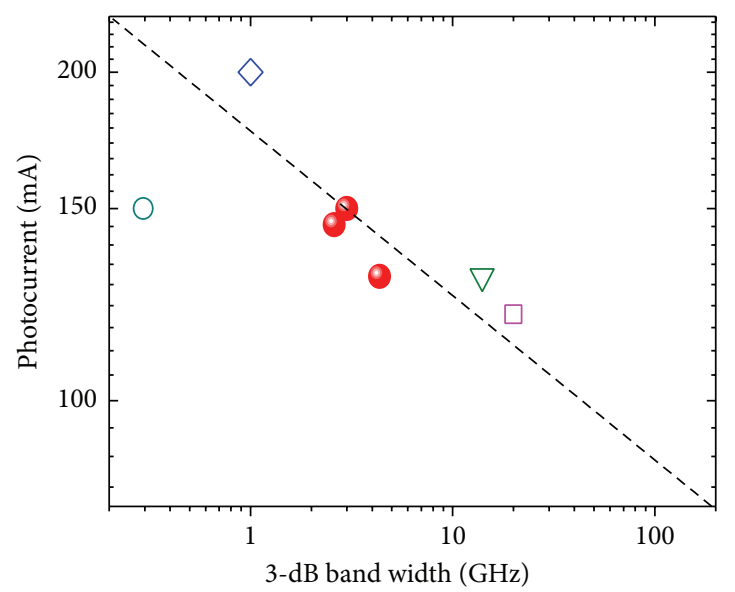

This work
$\diamond$ PDA-PD [5]
$\square$ UTC-PD [9]

$\nabla$ MUTC-PD [20]

○ High current PD [22]

(b)

FIGURE 4: (a) RF response of different diameter MUTC-PD devices at $5 \mathrm{~V}$, inset shows the optical image of device under test, and (b) shows the comparison of high power MUTC-PD with the various similar high power devices in literature [5, 9, 20, 22].

top surface. InGaAs-InP MUTC photodetector devices with charge-compensated collector layer with high photocurrent and fast response has been demonstrated. Our large device with diameter of $80 \mu \mathrm{m}$ can achieve high photocurrent of $150 \mathrm{~mA}$ with $-3 \mathrm{~dB}$ bandwidth of $\sim 3 \mathrm{GHz}$. Suitable ARC coating, back side illumination, and thicker absorption layer can further improve the device responsivity. The RF response of the larger devices is mainly limited by the RC-limited bandwidth due to thin collection layer and can be further improved by minimizing series resistance, optimizing structure design, and using heat sink for cooling the device under test.

\section{Conflict of Interests}

The authors declare that there is no conflict of interests regarding the publication of this paper.

\section{Acknowledgments}

The authors would like to thank Ang Kian Siong for helping in device fabrication and Dr. Liu Chongyang for insightful discussion.

\section{References}

[1] N. Li, X. Li, S. Demiguel et al., "High-saturation-current chargecompensated InGaAs-InP uni-traveling-carrier photodiode," IEEE Photonics Technology Letters, vol. 16, no. 3, pp. 864-866, 2004.

[2] E. Rouvalis, M. Chtioui, M. Tran et al., "High-speed photodiodes for InP-based photonic integrated circuits," Optics Express, vol. 20, no. 8, pp. 9172-9177, 2012.

[3] K. Swaminathan, L.-M. Yang, T. J. Grassman et al., "Metamorphic In020Ga0. 80As p-i-n photodetectors grown on GaAs substrates for near infrared applications," Optics Express, vol. 19, no. 8, pp. 7280-7288, 2011.

[4] Z. Li, Y. Fu, M. Piels et al., "High-power high-linearity flipchip bonded modified uni-traveling carrier photodiode," Optics Express, vol. 19, no. 26, pp. B385-B390, 2011.

[5] D. A. Tulchinsky, X. Li, N. Li, S. Demiguel, J. C. Campbell, and K. J. Williams, "High-saturation current wide-bandwidth photodetectors," IEEE Journal on Selected Topics in Quantum Electronics, vol. 10, no. 4, pp. 702-708, 2004.

[6] F. J. Effenberger and A. M. Joshi, "Ultrafast, dual-depletion region, InGaAs/InP p-i-n detector," Journal of Lightwave Technology, vol. 14, no. 8, pp. 1859-1864, 1996. 
[7] K. Kato, S. Hata, K. Kawano, and A. Kozen, "Design of ultrawide-band, high-sensitivity $\mathrm{p}$-i-n photodetectors," IEICE Transactions on Electronics, vol. E76-C, no. 2, pp. 214-221, 1993.

[8] H. Ito, S. Kodama, Y. Muramoto, T. Furuta, T. Nagatsuma, and T. Ishibashi, "High-speed and high-output InP-InGaAs unitraveling-carrier photodiodes," IEEE Journal on Selected Topics in Quantum Electronics, vol. 10, no. 4, pp. 709-727, 2004.

[9] X. Wang, N. Duan, H. Chen, and J. C. Campbell, "InGaAs-InP photodiodes with high responsivity and high saturation power," IEEE Photonics Technology Letters, vol. 19, no. 16, pp. 1272-1274, 2007.

[10] H.-J. Song and T. Nagatsuma, "Present and future of terahertz communications," IEEE Transactions on Terahertz Science and Technology, vol. 1, no. 1, pp. 256-263, 2011.

[11] S. Koenig, D. Lopez-Diaz, J. Antes et al., "Wireless sub-THz communication system with high data rate," Nature Photonics, vol. 7, no. 12, pp. 977-981, 2013.

[12] T. Nagatsuma, H. Ito, and T. Ishibashi, "High-power RF photodiodes and their applications," Laser and Photonics Reviews, vol. 3, no. 1-2, pp. 123-137, 2009.

[13] A. S. Jordan, A. Robertson, and J. L. Zilko, “Thermodynamic interpretation of quaternary (InGaAsP) layer uniformity grown by low-pressure metalorganic vapor phase epitaxy," Applied Physics Letters, vol. 62, no. 4, pp. 360-362, 1993.

[14] D. Keiper, R. Westphalen, and G. Landgren, "Metal organic vapour-phase epitaxy (MOVPE) growth of InP and InGaAs using tertiarybutylarsine (TBA) and tertiarybutylphosphine (TBP) in $\mathrm{N}_{2}$ ambient," Journal of Crystal Growth, vol. 204, no. 3, pp. 256-262, 1999.

[15] D. Keiper and R. Westphalen, "Effect of the carrier gas and the group-V precursor on the DEZn doping efficiency for InP and In0.54Ga0.46As in LP-MOVPE," Journal of Crystal Growth, vol. 233, no. 1-2, pp. 126-131, 2001.

[16] M. Horita, M. Suzuki, and Y. Matsushima, "MOVPE growth of in GaAsP using TBA and TBP with extremely low V/Ill ratio," in Proceedings of the 6th International Conference Metalorganic Vapor Phase Epitaxy, pp. 191-192, June 1992.

[17] P. Enquist, J. A. Hutchby, and T. J. Lyon, "Growth and diffusion of abrupt $\mathrm{Zn}$ profiles in gallium arsenide and heterojunction bipolar transistor structures grown by MOVPE," Journal of Applied Physics, vol. 63, pp. 4485-4493, 1988.

[18] Q. Zhou, A. S. Cross, A. Beling, Y. Fu, Z. Lu, and J. C. Campbell, "High-power V-band InGaAs/InP photodiodes," IEEE Photonics Technology Letters, vol. 25, no. 10, pp. 907-909, 2013.

[19] A. Kaminski, J. J. Marchand, A. Fave, and A. Laugier, "New method of parameters extraction from dark I-V curve," in Proceedings of the Conference Record of the 26th IEEE Photovoltaic Specialists Conference, pp. 203-206, Anaheim, Calif, USA, September 1997.

[20] M. Chtioui, A. Enard, D. Carpentier et al., "High-performance uni-traveling-carrier photodiodes with a new collector design," IEEE Photonics Technology Letters, vol. 20, no. 13, pp. 1163-1165, 2008.

[21] N. Duan, X. Wang, N. Li, H.-D. Liu, and J. C. Campbell, "Thermal analysis of high-power InGaAs-InP photodiodes," IEEE Journal of Quantum Electronics, vol. 42, no. 12, pp. 12551258, 2006.

[22] G. A. Davis, R. E. Weiss, R. A. LaRue, K. J. Williams, and R. D. Esman, "A 920-1650-nm high-current photodetector," IEEE Photonics Technology Letters, vol. 8, no. 10, pp. 1373-1375, 1996. 

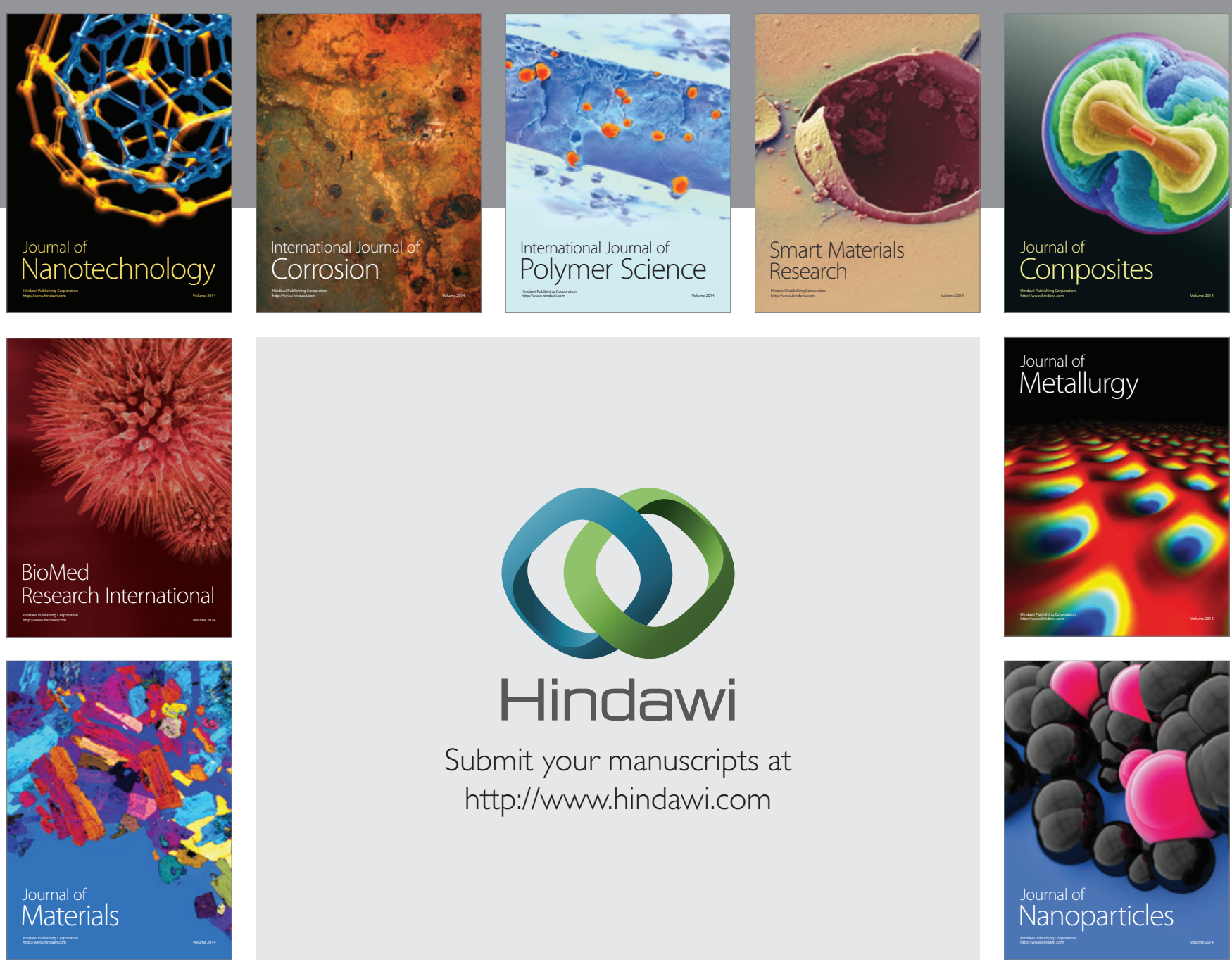

Submit your manuscripts at http://www.hindawi.com
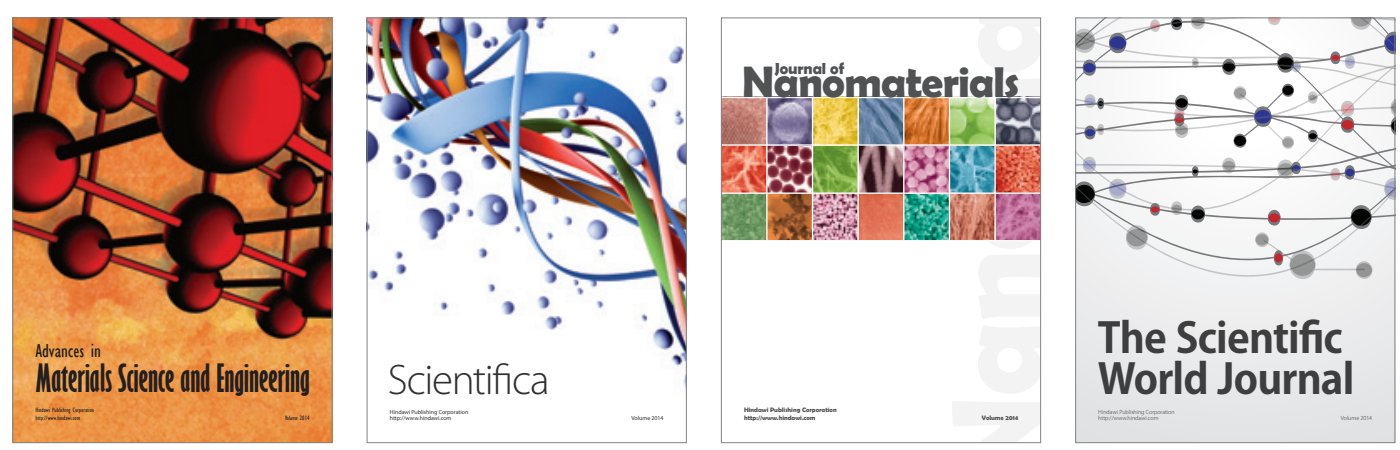

\section{The Scientific World Journal}
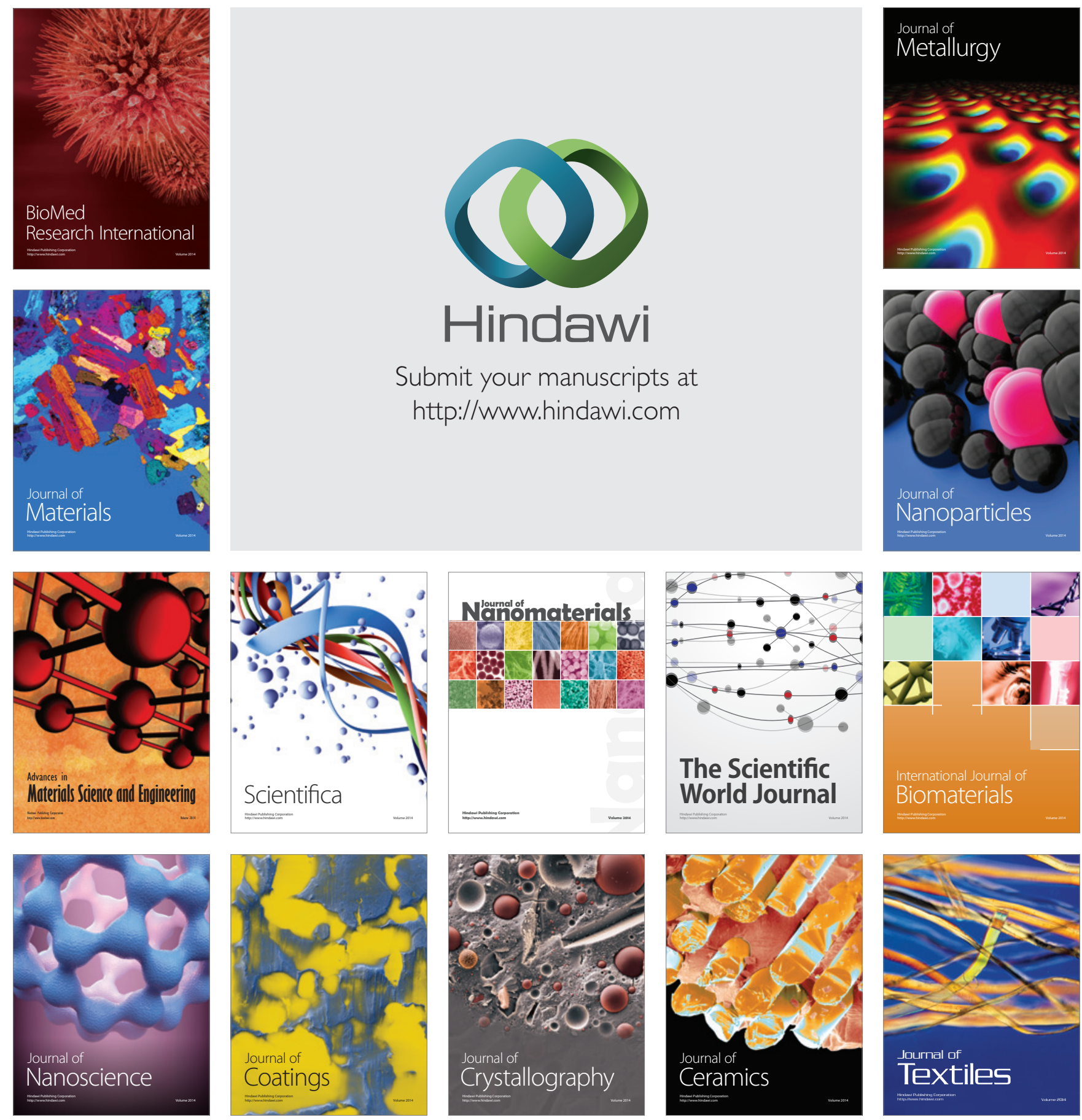